\title{
Quasi-Static Flexural Properties of a Pultruded Glass Fiber/Unsaturated Polyester Square Pipe
}

\section{Yuri Imai', Gabriel Fortin ${ }^{1}$, Badin Pinpathomrat', Keigo Nishitani' ${ }^{1}$, Anin Memon ${ }^{2}$, Yuqiu Yang , Akio Ohtani' ${ }^{1}$, Hiroyuki Hamada ${ }^{1}$}

\author{
${ }^{1}$ Department of Advanced Fibro-Science, Kyoto Institute of Technology, Kyoto, Japan \\ ${ }^{2}$ Department of Industrial Engineering, Faculty of Engineering, Rajamangala University of Technology Thunyaburi, Phathumtani, \\ Thailand \\ ${ }^{3}$ Key Laboratory of Textile Science \& Technology, Ministry of Education, College of Textiles, Donghua University, Shanghai, \\ China \\ Email: ^ga briel.fortin5@gmail.com
}

How to cite this paper: Imai, Y., Fortin, G., Pinpathomrat, B., Nishitani, K., Memon, A., Yang, Y., Ohtani, A. and Hamada, H. (2019) Quasi-Static Flexural Properties of a Pultruded Glass Fiber/Unsaturated Polyester Square Pipe. Open Journal of Composite Materials, 9, 271-284.

https://doi.org/10.4236/ojcm.2019.93016

Received: May 23, 2019

Accepted: July 7, 2019

Published: July 10, 2019

Copyright $\odot 2019$ by author(s) and Scientific Research Publishing Inc. This work is licensed under the Creative Commons Attribution International License (CC BY 4.0).

http://creativecommons.org/licenses/by/4.0/

\begin{abstract}
This paper explores quasi-static flexural properties and fracture behavior of a pultruded glass fiber/unsaturated polyester square pipe for automotive structural applications. Three-point flexural testing is performed in an Instron Universal Testing Machine with steel jigs supporting the top and bottom surfaces of the pipe. Acoustic emission (AE) measurements are recorded during flexural testing to evaluate initial fracture in the pipe structure. After final fracture, five cross-sections of the pipe are cut at $50-\mathrm{mm}$ intervals along the longitudinal axis, with the first cut located at the mid-span of the pipe. Cross-sections of a pipe from an interrupted test where initial fracture is detected from the AE method are also prepared. Damage locations and behavior on each cross-section are observed. The flexural testing results show that the cumulative AE counts increase rapidly from $2.5 \mathrm{kN}$, that final failure occurs at a maximum load of approximately $13 \mathrm{kN}$, and that corresponding initial and final failure occurs in the two corner regions on the compressive side of flexural loading. Failure initiates by stress concentrations due to the upper jig on the top surface during bending. The cross-sectional observations also reveal clear deformation behavior of the pipe where failure is present, marked by inward bending of the top surface and upper corners located on the compressive side, near the jig. The locations of maximum stresses and deformations obtained from finite element analysis of this pipe structure are in very good agreement with the experimental observations.
\end{abstract}

\section{Keywords}

Automotive Composites, Flexural Testing, Pultruded Pipe, Mechanical 
Strength, Fracture Behavior

\section{Introduction}

Reducing $\mathrm{CO}_{2}$ emissions from automobiles is an important issue as a measure against global warming. The latest reports show that approximately 76 million cars are expected to be produced in the world annually by 2020, corresponding to 208,000 cars every single day of the year [1]. Clearly, weight reduction and improved fuel efficiency in service of automobile parts using lightweight materials with high mechanical properties are an important requirement. It is estimated that 75 percent of fuel consumption directly relates to vehicle weight, and a 6 - 8 percent increase in fuel consumption can be realized for every 10 percent reduction in weight [2] [3] [4]. Materials such as fiber-reinforced plastics are excellent candidates as they consist of relatively high-strength and stiffness fibers such as glass, carbon, or aramid, that are impregnated in a polymer matrix resin, and their use in the automotive industry is projected to grow in years ahead [3] [5] [6] [7] [8]. Fiber-reinforced composites are lightweight, stiff, and strong materials with properties that can be tailored for optimal load paths. They are also unique in that complex shapes that are impossible with metals can be produced [4] [9] [10]. For automotive applications, carbon and glass reinforcements are popular choices for structural components.

A manufacturing process such as pultrusion is very well suited to produce long structural components with a constant cross-section [11] [12] [13]. In pultrusion of thermoset composites, dry fibers are impregnated with a liquid polymer of low viscosity, and are then pulled through a heated die to cross-link the matrix and form the part [14]. This is a well known and established continuous manufacturing process. Moreover, reinforcing fibers in the form rovings, continuous filament mats, woven fabrics, or braided preforms can be used through the thickness of pultruded parts [11]. The pultrusion process for manufacturing automotive composites offers considerable advantages from an environmental perspective as well. Song et al. [15] performed a life cycle analysis to estimate the energy requirements for producing pultruded composite structures for the automotive industry. Their findings have shown that pultruded composite parts can save energy compared to using steel for automotive structural parts [15].

When testing the mechanical properties of a structure, additional information on fracture development within a material can be obtained real-time by acoustic emission (AE) testing. AE testing is a non-destructive technique that allows for real-time monitoring of fractures occurring in a material. $\mathrm{AE}$ is an elastic wave that is emitted when local deformations or crack propagation occurs in a material [16] [17] [18]. Important measurement parameters in AE testing are the signal amplitude, cumulative counts, and the AE energy [16]. The AE amplitude is the peak voltage of a signal waveform from an emission event. It is an important 
parameter for detectability, related to the magnitude of a source event [19]. The number of counts refers to the total number of oscillations of AE waves that exceed a specified threshold value. The AE energy is the total elastic transient energy released by an emission event. It is sensitive to amplitude and duration of the signal, as well as being dependent on operating frequencies and signal threshold. It is used more frequently to report magnitudes of source events over counts [19] [20].

A large number of studies on the mechanical properties of pultruded composite structures have been performed in the literature; however the relationship between the initial fracture stress and the fatigue limit must be clarified. As part of a study to better understand this relationship, an experimental investigation is performed on a pultruded square pipe with a laminated structure at a structural level. Another study in parallel to this one aims to predict the fatigue limit of this material based on the initial fracture stress obtained in static mechanical testing, using test specimens that are cut from the pipe structure in this study. The results in both studies will contribute to a better understanding of how the fatigue limit can be predicted from the initial fracture stress. For the structural automotive application of this pipe structure, these properties must be well understood in order to effectively determine a suitable safety factor. With weight constraints that must be met, this safety factor should be minimized as required.

The objectives of this research are to evaluate the quasi-static flexural properties and fracture behavior of a pultruded glass fiber/unsaturated polyester square pipe for automotive structural applications. AE testing is performed during flexural tests to gain additional information on fracture development within the structure. Particular attention is drawn to the initial fracture. Microscale fracture such as interfacial debonding, filament fracture, and so on is closely related to the initial fracture stress which marks the beginning of the non-linear stress strain relation. However, detecting the initial fracture stress from the stress-strain curve is difficult. In this paper, the AE method is introduced and cross-sectional observation is performed. Throughout discussion of the initial fracture stress and fracture aspects, further structural designs are proposed.

\section{Experimental Procedures}

\subsection{Materials}

The pipes in this project are made from glass fiber-reinforced unsaturated polyester with a total length of $1400 \mathrm{~mm}$, wall thickness of $2.4 \mathrm{~mm}$. Details on the square pipe geometry with dimensions are presented in Figure 1. The outside corner radius is $5 \mathrm{~mm}$, and because there is no inside corner radius, the length of the straight section at the inside corner is defined as $3 \mathrm{~mm}$. As shown in the figure, the pipe walls are made of a laminated structure with the following 5 layers: a combination of a chopped strand mat and screen type mat on the two outside layers, followed by a screen type mat on the second layers, and unidirectional (UD) fibers oriented along the longitudinal axis of the pipe ( $0^{\circ}$ direction) in the 


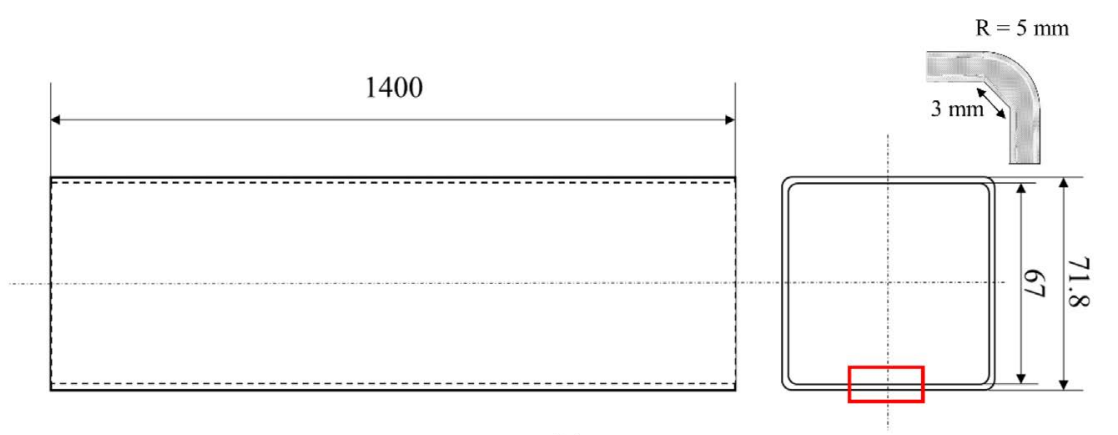

(a)
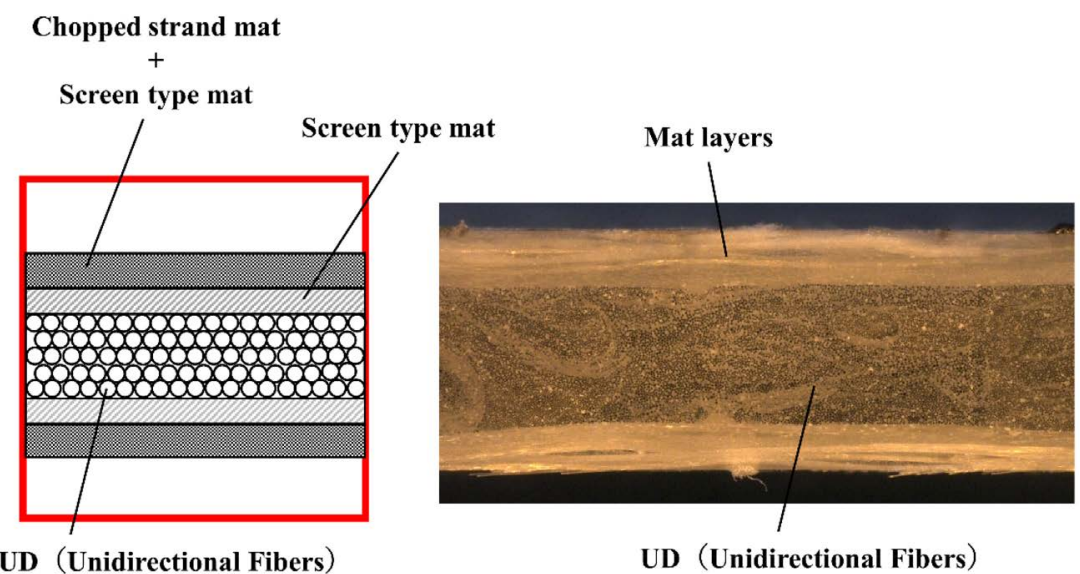

UD（Unidirectional Fibers）

(b)

Figure 1. (a) Square pipe geometry and dimensions (dimensions in $\mathrm{mm}$ ); (b) Cross-section sketch and microscopy image of laminated structure.

inner-most layer. A sample image taken by optical microscopy of this laminated structure is also shown in Figure 1.

\subsection{Mechanical Characterization}

Quasi-static three-point bending tests were performed on the pipes in an Instron Universal Testing Machine type 55R4206 at room temperature with a 10-ton load cell. The cross-head speed of the test was set to $20 \mathrm{~mm} / \mathrm{min}$. The square pipe was positioned within three U-shaped steel jigs where loads were applied, and the span length for testing was set to $800 \mathrm{~mm}$. Details on the jig dimensions and mounting positions on the pipe for flexural testing are presented in Figure 2. This U-shaped steel jig was developed to avoid compressive and buckling fracture just below the normal loading jig. At the mid-span of the pipe on the underside, corresponding to the tensile surface during flexural loading, an $\mathrm{AE}$ sensor (Nippon Physical Acoustics, Inc., micro-30) was positioned for recording data on crack propagation during testing. Load-displacement data and amplitudes generated from crack formation were measured. The threshold value for $\mathrm{AE}$ amplitude measurements was set to $55 \mathrm{~dB}$ to eliminate extraneous noise.

When bending loads are applied on the structure, localized sources of crack initiation and propagation within the material will trigger the release of energy, 


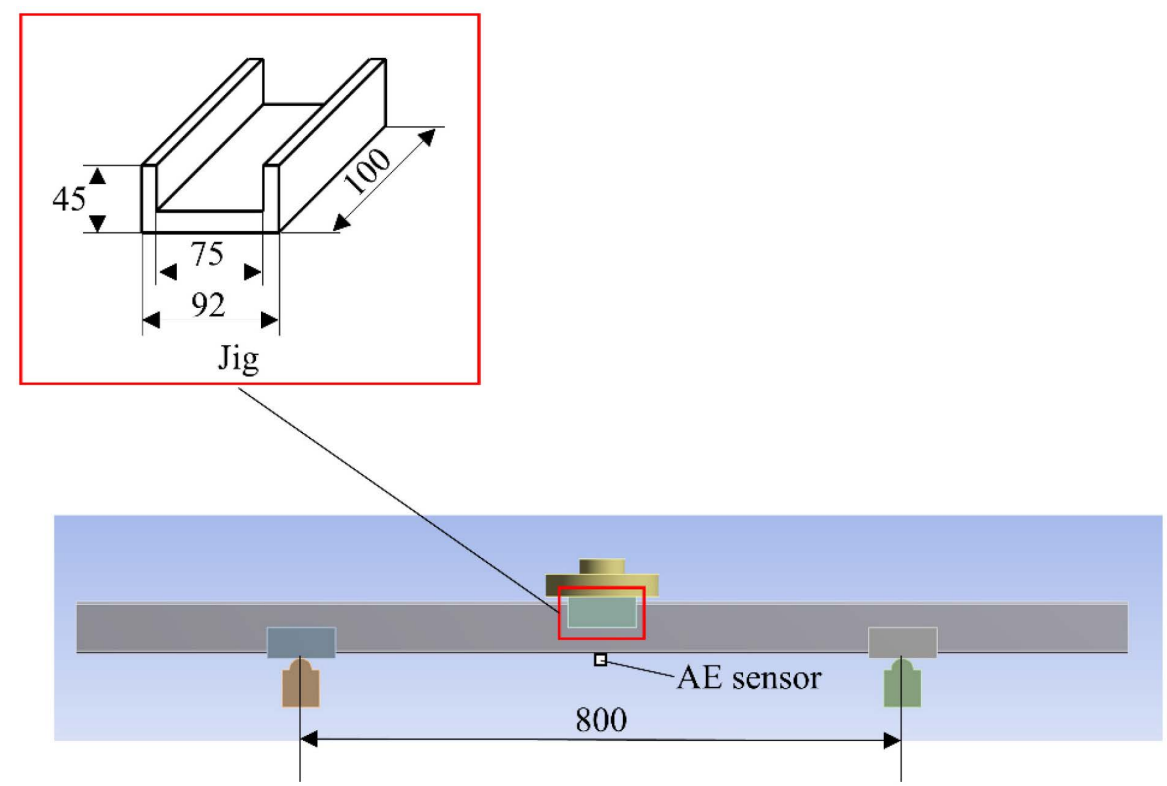

Figure 2. Jig mounting position of square pipe bending test (dimensions in $\mathrm{mm}$ ).

in the form of elastic waves. These elastic waves will travel to the surface and will be detected by the AE sensor [21]. The AE sensor is composed of piezoelectric elements and is able to detect types and sources of failure in real time. In this case, acoustic emissions will be detected to determine the onset of damage initiation within the pipe structure during quasi-static flexural testing.

\subsection{Damage Characterization}

After flexural testing, cross-sections of the pipe at $50-\mathrm{mm}$ intervals along the longitudinal axis were cut, beginning at the mid-span of the pipe (first cut) and ending at a final cut distance of $200 \mathrm{~mm}$, for a total of five cuts. The cross-sections were polished and observed by optical microscopy for determining locations of fracture along the pipe. Due to the symmetry in load distributions from the mid-span, cross-sectional observation was performed along one half of the pipe only. Deformation behavior of the pipe walls was also observed from the cross-section segments.

Cross-sections of a pipe from an interrupted flexural test were also prepared for assessing the initial fracture condition, based on the results of the AE measurements performed.

\section{Results and Discussion}

\subsection{Flexural Loading and Acoustic Emission Measurements}

Flexural load-displacement data of the pipe with the recorded AE amplitude measurements are presented in Figure 3, as well as AE energy measurements and cumulative $\mathrm{AE}$ counts in Figure 4 and Figure 5, respectively. The load-displacement curve shows that failure of the pipe occurs at approximately $13 \mathrm{kN}$, at a displacement of $11.6 \mathrm{~mm}$. The data shows linear behavior until a 


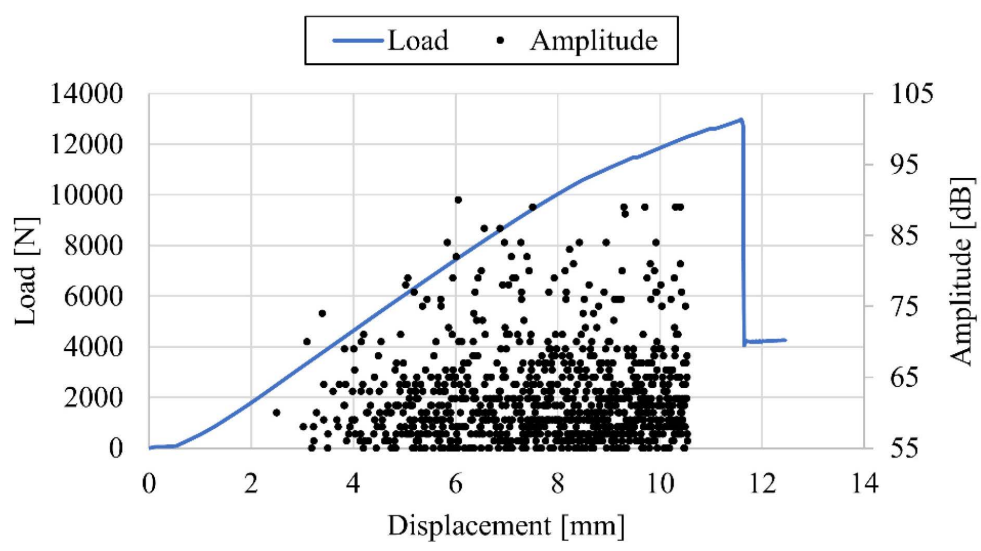

Figure 3. Relationship between square pipe bending test and AE amplitude.

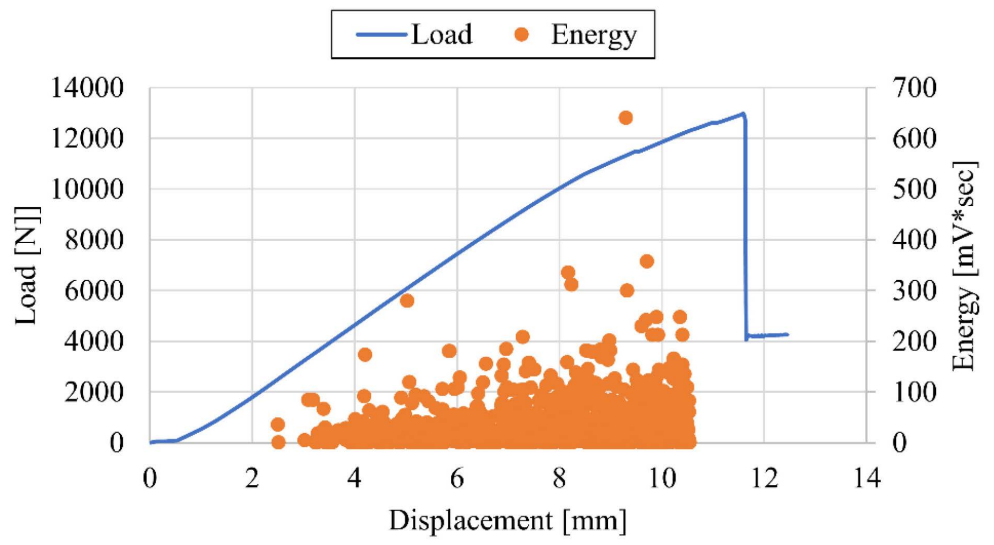

Figure 4. Relationship between square pipe bending test and AE energy.

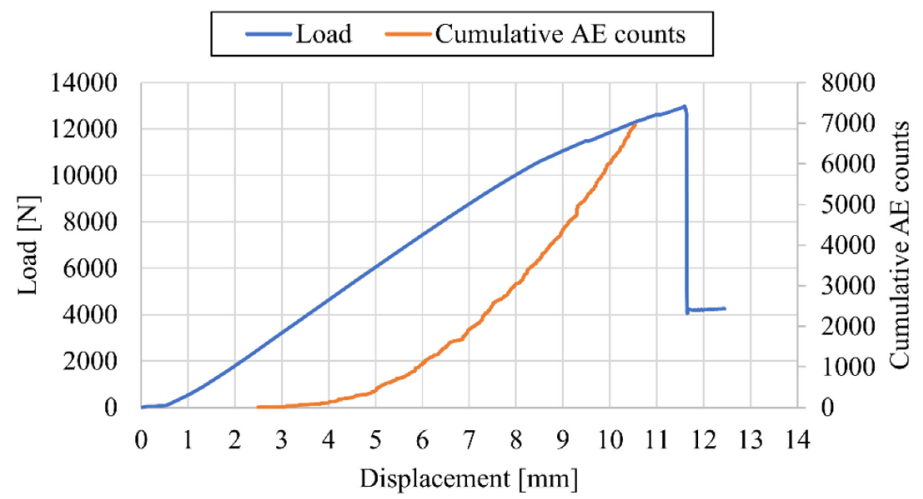

Figure 5. Relationship between square pipe bending test and cumulative AE counts.

displacement of $6 \mathrm{~mm}$, after which point it transitions to non-linear behavior followed by final fracture. Figure 3 shows that the recorded maximum amplitude values increase with increasing load, up to a value of $90 \mathrm{~dB}$ first reached at 6 $\mathrm{mm}$ of displacement, with a larger number of amplitude events being more concentrated in the range of $55-70 \mathrm{~dB}$ throughout testing. Figure 4 shows a clear trend in increasing acoustic energy values with increasing displacement as well. 
From Figure 5, it is very clear that the cumulative AE counts number rapidly increases from approximately $2.5 \mathrm{kN}$. This corresponding load value will be used as the load limit of the interrupted test for observations of initial fracture in the following section.

\subsection{Microscopy Observations}

A sketch showing the locations where cross-section cuts were made for observation of the pipe after final fracture is presented in Figure 6. The jig position relative to the cuts is also indicated. The first cut was made at the mid-span of the pipe, at a reference position of $\mathrm{L}=0 \mathrm{~mm}$. The four corner sections along the pipe were also identified (A to D) as shown in the figure. The cross-sections revealed that failure was only present in the regions of corners $A$ and $B$, located on the compressive side of flexural loading. Therefore, optical microscopy images of corners A and B for all five sections are presented in Figures 7(a)-(e). Fracture regions are indicated by red arrows or outlined with markers. Sketches of the corner regions and fracture locations are also presented as required. In Figure 8, examples of fiber wrinkling that were observed in all cross-sections at the two bottom corners (corners $\mathrm{C}$ and $\mathrm{D}$ ) are shown. Fiber wrinkling was present in all sections, as a result of the manufacturing process in the as-received pipes.

Signs of fracture in corners A and B are observed in Sections 1 to 3 (Figures 7 (a)-(c)), while Sections 4 and 5 do not show any signs of fracture, meaning that fracture did not propagate this far along the pipe. The largest fractures are observed in section 2 (Figure 7(b)) located $50 \mathrm{~mm}$ from the mid-span of the pipe. As this section is located at the edge of the upper jig, it is likely that local stress concentrations were built up the most around this region.

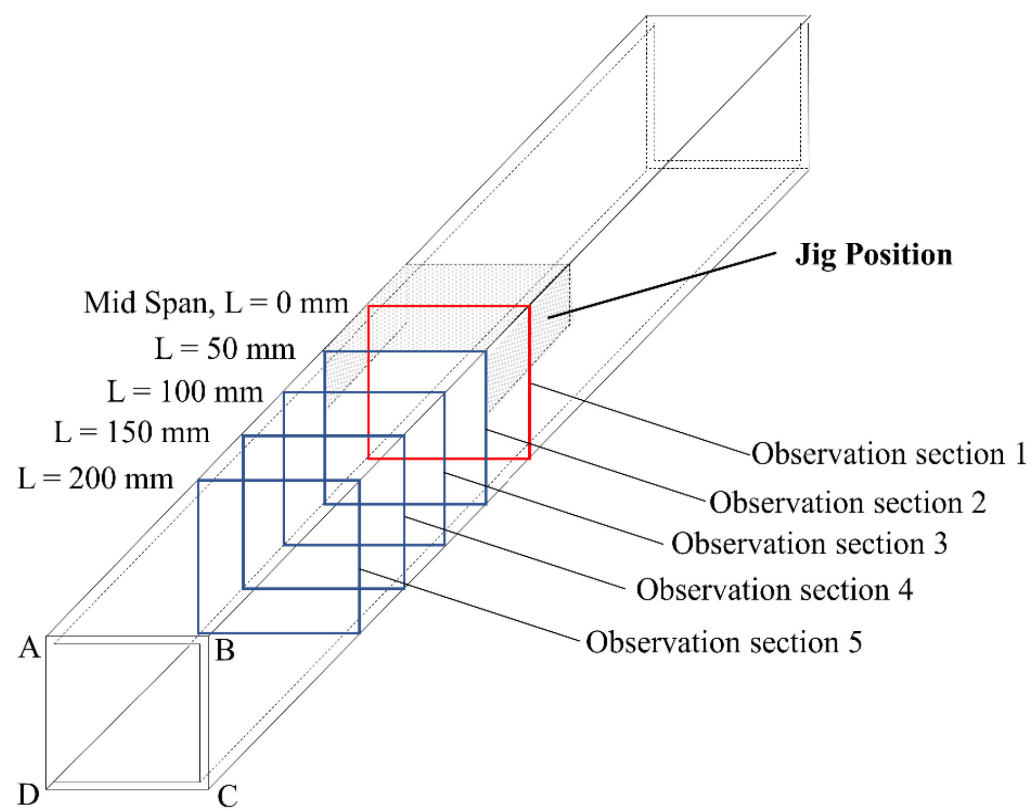

Figure 6. Sketch showing location of square pipe cross-sectional observations and Orientation of corners A, B, C, and D along the pipe. 

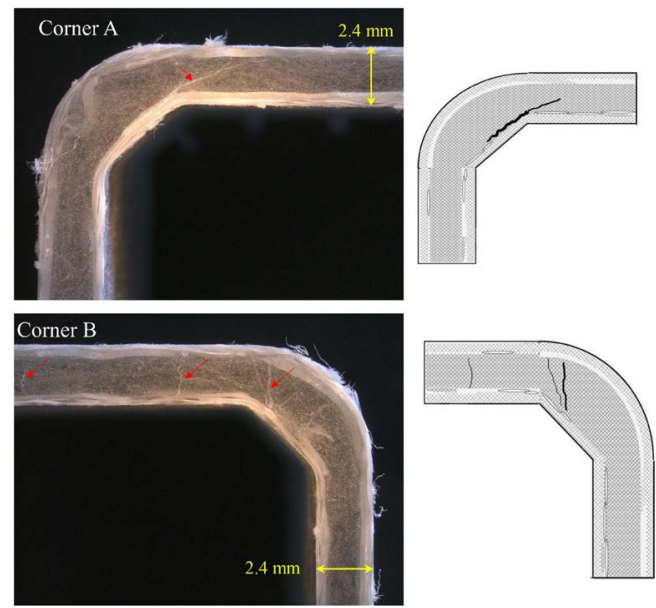

(a) Observation section 1

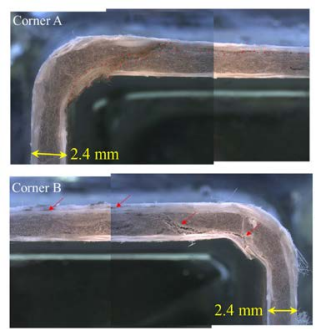

(b) Observation section 2
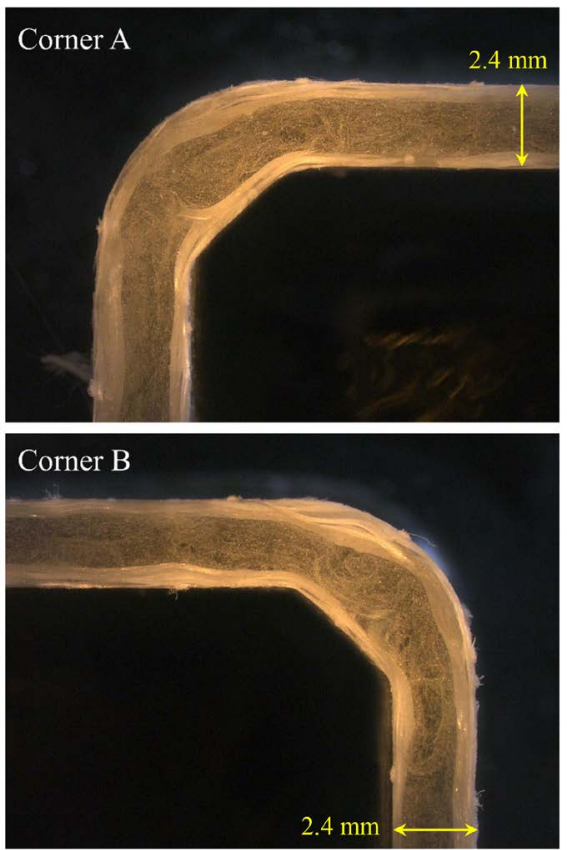

(d) Observation section 4
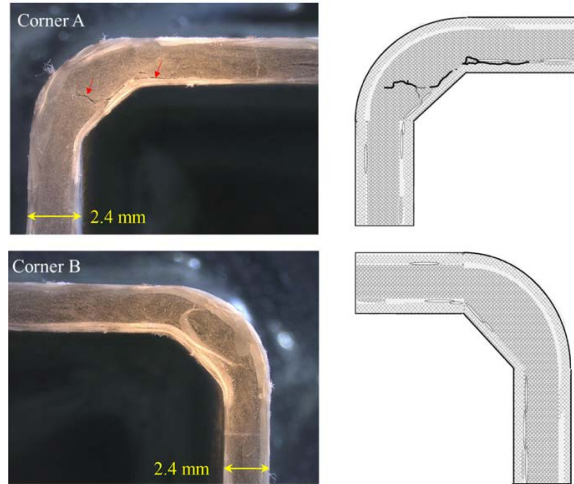

(c) Observation section 3
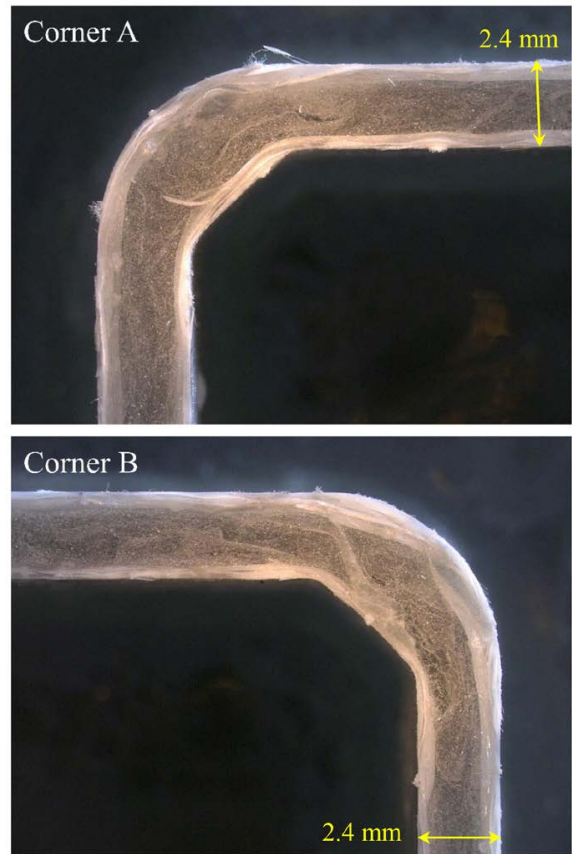

(e) Observation section 5

Figure 7. Cross-section observation of square pipe after final failure during flexural testing. 

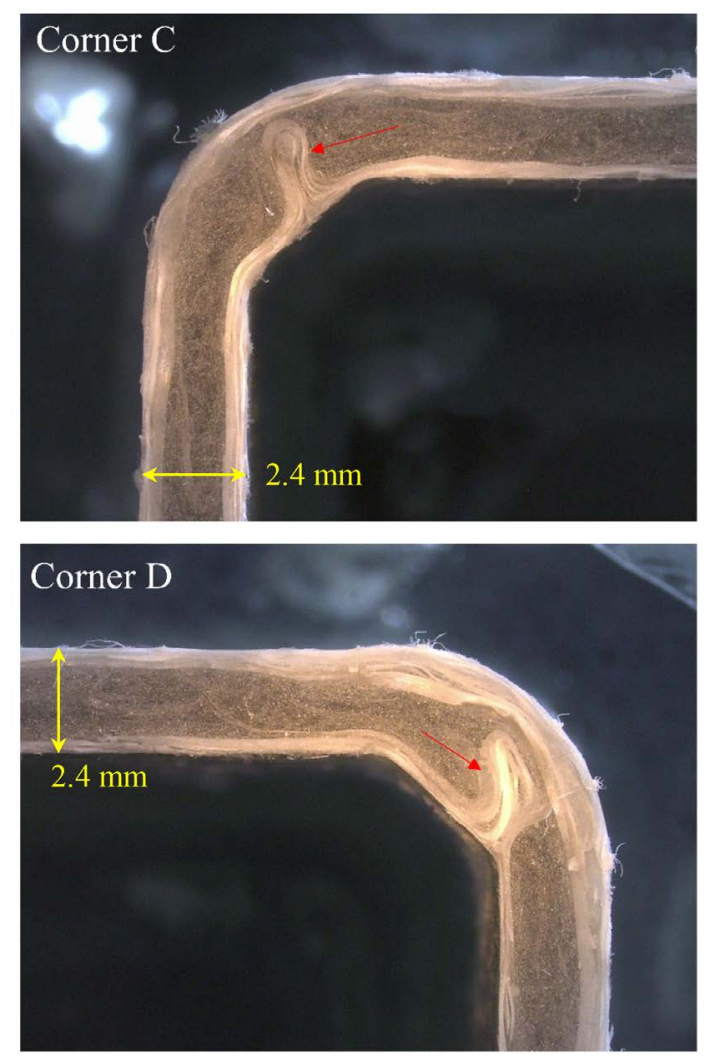

Figure 8. Corner wrinkling of fibers, as observed on corners $\mathrm{C}$ and $\mathrm{D}$ along the square pipe.

The observed fractures in the cross-sections in Figures 7(a)-(c) are transverse cracks within the unidirectional layer of the laminate structure, due to fracture at the interface between the fibers and resin. In addition, interlaminar failure is observed where separation occurs between the inner unidirectional layer and the adjacent screen-type mat layer. This is clearly observed in Figure 7(b), Figure 7 (c). It is likely that the transverse cracks initiated in the UD layer of the corners, and later propagated as interlaminar separation.

At cross-section 2, located at $50 \mathrm{~mm}$ from the mid-span of the pipe, directly under the edge of the upper steel jig, significant deformation is also observed on the two upper corners $\mathrm{A}$ and $\mathrm{B}$ as well as the upper surface. A cross-section schematic diagram of the deformation behavior at this section of the pipe is presented in Figure 9. The deformations are characterized by bending of the top surface downwards, as well as the top two corners being bent inwards. These deformations are observed because a moment acts on the corners due to the application of the load by the jig, causing the observed curvature in the upper flat section of the pipe and inward displacement of the corners.

Cross-section microscopy images taken from a pipe after an interrupted bending test at the onset of rapid cumulative AE counts at Sections 1 and 2 are presented in Figure 10. In this pipe, signs of initial fracture can be observed in both sections, in the upper corner regions as in the pipe tested until final failure. 


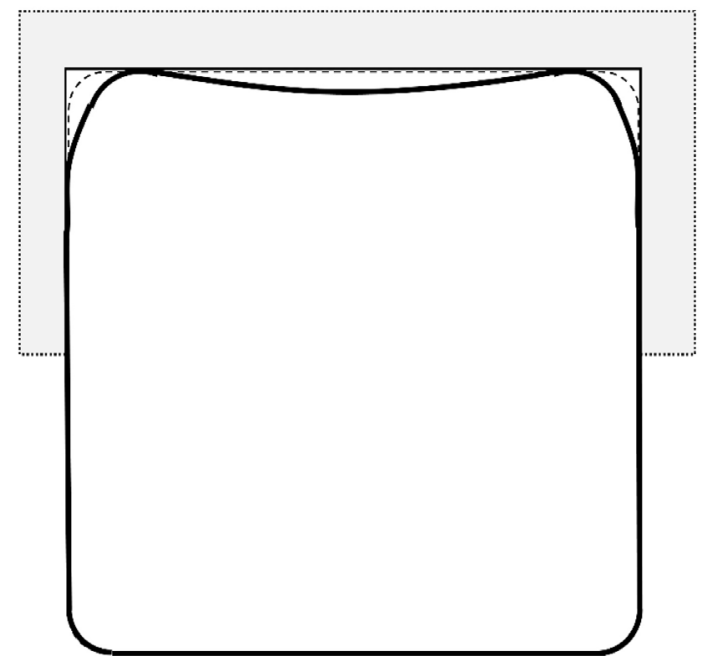

Figure 9. Cross-section schematic diagram of deformation behavior on center section of square pipe.

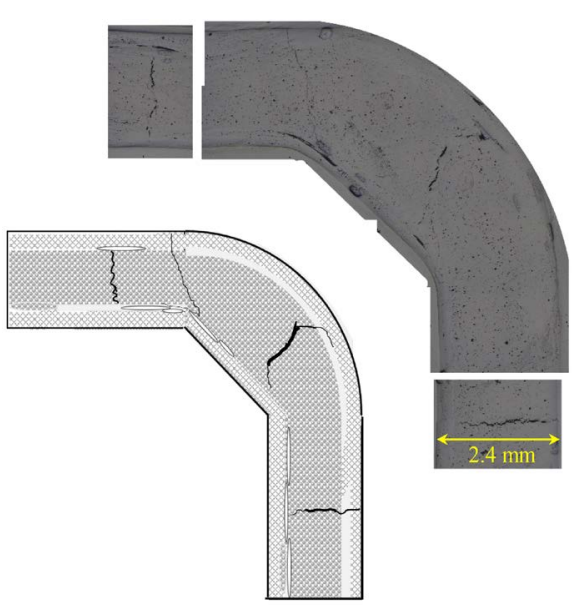

(a) Observation section 1

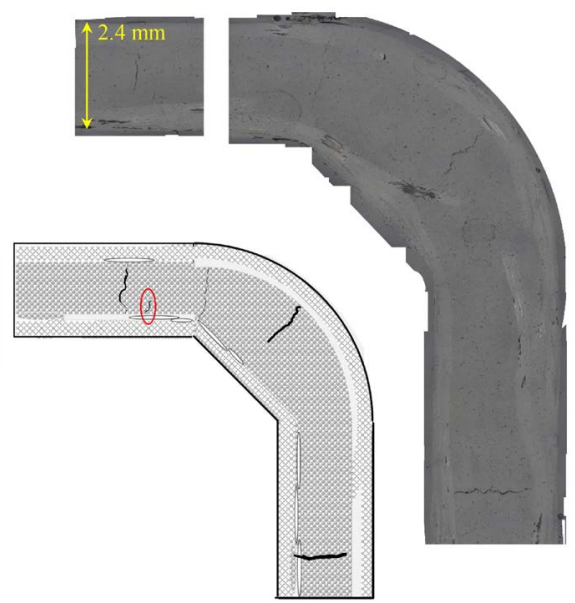

(b) Observation section 2

Figure 10. Cross-section observation of square pipe after interrupted flexural test.

It is very clear that cracks initiate in the corner regions, and the $\mathrm{AE}$ results correspond to crack growth in the corner regions of the pipe, until final fracture.

Finite element analysis results showing the deformation behavior of the square pipe during three-point flexural testing are presented in Figure 11. The simulation was performed in ABAQUS, and the model consisted of 17,009 nodes, 16,864 elements, and mesh size of $5 \mathrm{~mm}$. As the purpose of this simulation was to study the fracture aspects and locations based on pipe geometry, the model consisted of a homogeneous material with the same dimensions as the physical pipe in this study. The maximum failure load of the simulated pipe was $21 \mathrm{kN}$.

The results show that maximum deformation occurs at the corners in contact with the jig. It can also be seen that the deformation of the pipe extends longitudinally along the two upper corners. These results are in good agreement with 

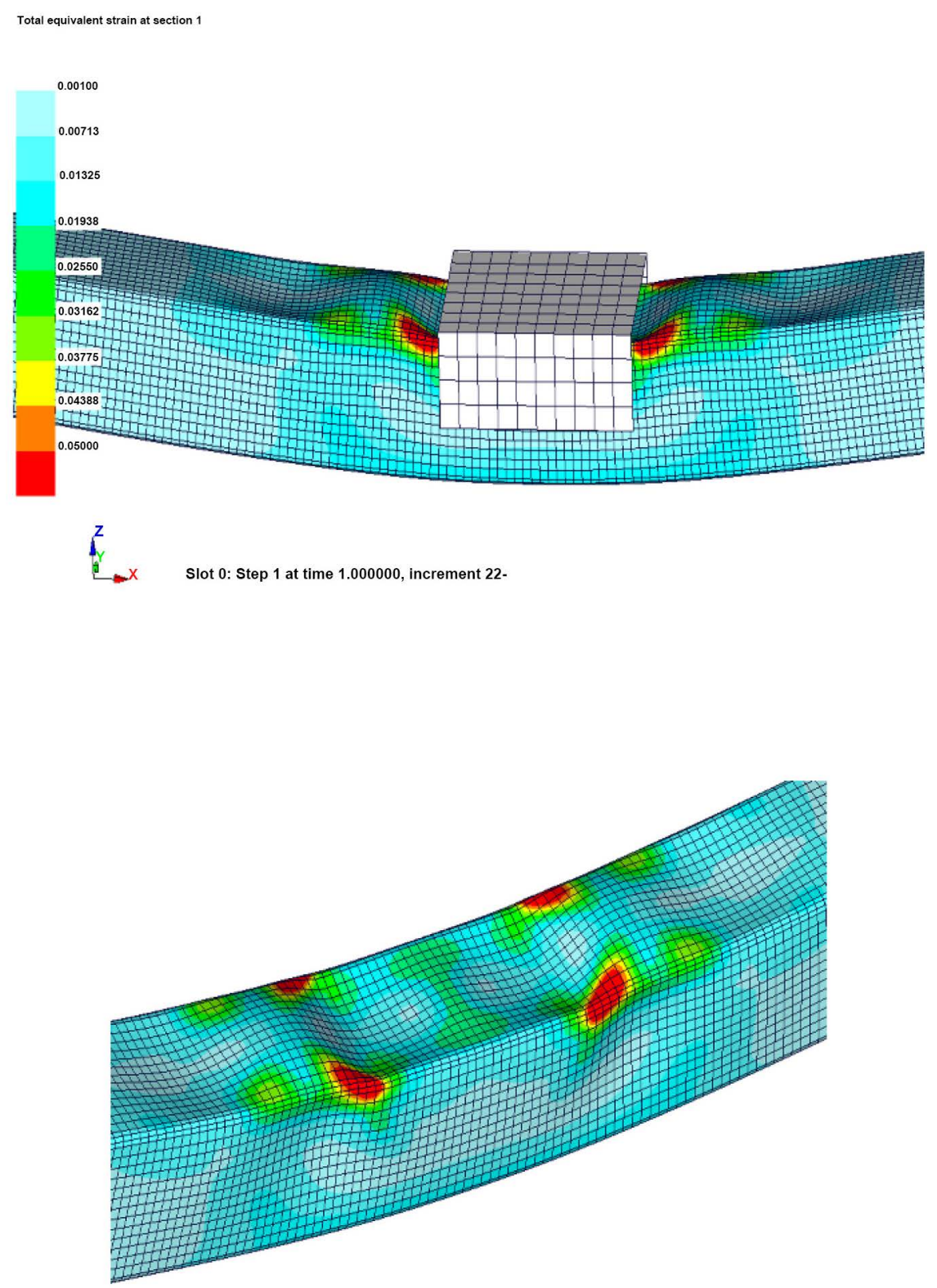

Figure 11. Finite element analysis results of deformation behavior on square pipe.

the observed deformations in cross-section 2 (Figure 9), and with the fracture observations of Figure 7 and Figure 10, showing failure in the corner regions.

When evaluating the flexural properties of the square pipe, variations in experimental design, materials design, structural design, and processing design should be considered. It is very clear from the obtained results that experimental design plays a critical role in the stress and deformations applied on the square pipe. The current jig consists of square edges, and alternate designs should be considered when performing bending tests in the future. The jig design should minimize local deformations in the structure. Another option would be to insert a metal plate that has the same shape and size as the inside cross-section of the pipe, so that it closely fits inside the pipe and prevents the walls of the pipe from 
bending inwards during testing. The reinforcing plate should be placed where deformations are greatest near the mid-span of the pipe.

In terms of materials design, variations in the laminated structure layer compositions can always be considered to optimize properties. Structural design would involve changes in pipe geometry, including wall thickness, and corner inner and outer radii. For example, one option would be increasing the thickness of the straight wall sections of the pipe to increase rigidity, and to reduce corner thickness with the aim to minimize stress build-up in these regions. However, it should be noted that variations in structural and materials design are directly related to processing design. In this case, the limitations of manufacturing composite square pipes by the pultrusion method should be considered. For example, certain geometries in pipe cross-section geometries may not be possible with the current manufacturing processes.

\section{Conclusions}

Quasi-static three-point bending was performed on a pultruded square pipe made of glass fiber-reinforced polyester for an automotive structural application. The AE method was applied during testing to evaluate initial fracture, and cross-section observations were performed after testing to investigate fracture locations and deformation behavior. The experimental findings were compared with a finite element simulation. This study showed that:

- Fracture occurs within the two corner regions of the pipe on the upper (compressive side of flexural loading), and is characterized by the presence of transverse cracks within the UD layer of the laminated structure as well as interlaminar cracks in between the UD layer and adjacent screen type mat layers.

- Cross-sections 1, 2, and 3 of the pipe after final fracture located at mid-span, $50 \mathrm{~mm}$, and $100 \mathrm{~mm}$ from mid-span, respectively, contained fractures in the corner regions. The most significant fractures were observed in Section 2, located at the edge of the steel jig on the top surface of the pipe. Maximum deformations of the pipe marked by downward bending of the top surface and inward bending of the upper corners are also observed at this cross-section. Initial fracture is also observed in the same corner regions from a pipe after interrupted testing, based on the AE results. Fracture clearly starts in the corners and propagates until final fracture.

- Finite element simulation results show that maximum deformations during testing occur at the upper corners of the pipe, at the edges of the upper jig. The deformations also extend along the longitudinal axis of the pipe at the corners. These results are in very good agreement with the observed fracture locations and deformations of the cross-section cuts.

\section{Conflicts of Interest}

The authors declare that there is no conflict of interest. 


\section{Funding}

This research received no specific grant from any funding agency in the public, commercial, or not-for-profit sectors.

\section{References}

[1] Davoodi, M.M., Sapuan, S.M., Ahmad, D., Ali, A., Khalina, A. and Jonoobi, M. (2010) Mechanical Properties of Hybrid Kenaf/Glass Reinforced Epoxy Composite for Passenger Car Bumper Beam. Materials \& Design, 31, 4927-4932. https://doi.org/10.1016/j.matdes.2010.05.021

[2] Friedrich, K. and Almajid, A.A. (2013) Manufacturing Aspects of Advanced Polymer Composites for Automotive Applications. Applied Composite Materials, 20, 107-128. https://doi.org/10.1007/s10443-012-9258-7

[3] Department of Energy (DOE). Energy Efficiency and Renewable Energy. https://www.energy.gov/articles/545-mpg-and-beyond-materials-lighten-load-fuel-e conomy

[4] Carpenter, J.A. (2008) Challenges and Opportunities for Automotive Composites. SPE Automotive Composites Conference and Exposition, Troy, 16-18 September 2008, CD-ROM Proceedings.

[5] Vaidya, U. (2011) Composites for Automotive, Truck and Mass Transit. DEStech Publ. Inc., Lancaster.

[6] Musselman, M. (2006) Automotive Composites. A Design and Manufacturing Guide. Ray Publishing, Wheat Ridge.

[7] Eller, R. (2004) Future Potential and Inter-Materials Competition in Lightweight Automotive Composites. SPE Automotive Composites Conference and Exposition, Troy, 14-15 September 2004, CD-ROM Proceedings.

[8] Fisher, M.M. (2007) Plastics Are for Cars after All the Rest of the Story. SPE Automotive Composites Conference and Exposition, Troy, 11-13 September 2007, CD-ROM Proceedings.

[9] Callister, W.D. (2007) Materials Science and Engineering: An Introduction. 7th Edition, John Wiley \& Sons, Inc., Hoboken.

[10] Hull, D. and Clyne, T. (1996) An Introduction to Composite Materials. 2nd Edition, Cambridge University Press, Cambridge. https://doi.org/10.1017/CBO9781139170130

[11] Haj-Ali, R. and Kilic, H. (2002) Nonlinear Behavior of Pultruded FRP Composites. Composites Part B: Engineering, 33, 173-191. https://doi.org/10.1016/S1359-8368(02)00011-2

[12] Suratno, B.R., Ye, L. and Mai, Y.-W. (1998) Simulation of Temperature and Curing Profiles in Pultruded Composite Rods. Composites Science and Technology, 58, 191-197. https://doi.org/10.1016/S0266-3538(97)00132-2

[13] Akil, H.M., De Rosa, I.M., Santulli, C. and Sarasini, F. (2010) Flexural Behaviour of Pultruded Jute/Glass and Kenaf/Glass Hybrid Composites Monitored Using Acoustic Emission. Materials Science and Engineering A, 527, 2942-2950. https://doi.org/10.1016/j.msea.2010.01.028

[14] Carlsson, A. and Astrom, B.T. (1998) Experimental Investigation of Pultrusion of Glass Fibre Reinforced Polypropylene Composites. Composites Part A: Applied Science and Manufacturing, 29A, 585-593. https://doi.org/10.1016/S1359-835X(97)00115-2 
[15] Song, Y.S., Youn, J.R. and Gutowski, T.G. (2009) Life Cycle Energy Analysis of Fiber-Reinforced Composites. Composites Part A: Applied Science and Manufacturing, 40, 1257-1265. https://doi.org/10.1016/j.compositesa.2009.05.020

[16] Zohora, F. (2016) Evaluation of Material Crack Using Acoustic Emission Technique. Master's Thesis, Queensland University of Technology, Brisbane.

[17] Ohtsu, M. (1996) The History and Development of Acoustic Emission in Concrete Engineering. Magazine of Concrete Research, 48, 321-330. https://doi.org/10.1680/macr.1996.48.177.321

[18] Finlayson, R.D., et al. (2001) Health Monitoring of Aerospace Structures with Acoustic Emission and Acousto-Ultrasonics. Insight-Wigston Then Northampton, 43, 155-158.

[19] Grosse, C. and Ohtsu, M. (2008) Acoustic Emission Testing: Basics for Research-Applications in Civil Engineering. Springer-Verlag, Berlin, Heidelberg. https://doi.org/10.1007/978-3-540-69972-9

[20] Huang, M., et al. (1998) Using Acoustic Emission in Fatigue and Fracture Materials Research. JOM, 50, 1-14.

[21] NDT Resource Center. The Collaboration for NDT Education, Iowa State University. http://www.ndt-ed.org 